\title{
Are Aboriginal people more likely to be diagnosed with more advanced cancer?
}

\author{
Aboriginal \\ people had \\ significantly \\ higher risks \\ of regional or \\ distant spread \\ for head and \\ neck cancer
}

ison Gibberd

Rajah Supramaniam $\mathrm{BSC}, \mathrm{MPH}($ Hons)

Anthony Dillon

$\mathrm{PhD}^{3}$

Bruce K Armstrong

DPhil, FRACP, FAFPHM

Dianne L O'Connell

BMaths(Hons), $\mathrm{PhD}^{2}$

1 University of Sydney,

Sydney, NSW.

2 Cancer Council NSW,

Sydney, NSW.

3 Australian Catholic

University,

Sydney, NSW.

4 Sax Institute,

Sydney, NSW.

rajahs@nswcc.org.au

doi: 10.5694/mjal4.00701
A ustralian Aboriginal people have poorer survival than non-Aboriginal people after diagnosis of most cancer types. ${ }^{1}$ Spread of disease at diagnosis is a major prognostic factor for cancer, and differences in spread of disease partly explain the disparities in cancer survival between Aboriginal and non-Aboriginal people. ${ }^{1,2}$

For all cancers combined, Aboriginal people are more likely to have advanced disease at diagnosis than non-Aboriginal people..$^{1,2}$ However, the incidences of cancers that tend to present at a later stage, such as lung cancer, are higher in Aboriginal people, while the incidences of other cancers, such as melanoma, which are predominantly localised when diagnosed, are lower in Aboriginal people than non-Aboriginal people..$^{1,2}$

Studies have examined differences in spread of disease at diagnosis between Aboriginal and non-Aboriginal people for individual cancer types, but the results have been inconsistent across studies and cancer types. ${ }^{3-7}$ While incidence by spread of disease has been reported separately for Aboriginal and nonAboriginal people resident in New South Wales, ${ }^{4}$ comparisons of these two groups have generally not taken into account differences in factors that are known to be associated with spread of disease at diagnosis, such as age and socioeconomic status. ${ }^{8,9}$

Despite its effect on cancer treatment options and survival, there are major gaps in our knowledge of the patterns of disease spread at diagnosis for Aboriginal people. The aim of this study was to investigate spread of cancer by cancer type to determine whether Aboriginal people in NSW were more likely than non-Aboriginal people to be diagnosed with more advanced cancer.

We use the descriptor Aboriginal throughout this report to refer to the original people of Australia and their descendants, as endorsed by

\section{Abstract}

Objective: To determine whether Aboriginal people in New South Wales were diagnosed with more advanced cancer than non-Aboriginal people.

Design, setting and participants: Cross-sectional study of cancer cases, excluding lymphohaematopoietic cancers and cancers of unknown primary site, diagnosed in NSW in 2001-2007.

Main outcome measure: Spread of disease at time of cancer diagnosis.

Results: Overall, $40.3 \%$ of 2039 cancers in Aboriginal people and $46.6 \%$ of 191954 cancers in non-Aboriginal people were localised at diagnosis. After adjusting for age, sex, year of diagnosis, area of residence and socioeconomic status, Aboriginal people had significantly higher risks of regional or distant spread for head and neck cancer, relative to localised spread, than non-Aboriginal people (regional: adjusted relative risk ratio [RRR], 1.89; 95\% Cl, 1.21-2.98; distant: adjusted RRR, 3.40; 95\% Cl, 1.856.05; $P<0.001)$. For breast, cervical and prostate cancers and melanoma, the risks of regional or distant spread were higher for Aboriginal people, but these differences were not statistically significant. For lung, colorectal, upper gastrointestinal tract, other gynaecological, and eye, brain and central nervous system cancers, the risks of regional, distant and unknown spread of cancer were similar for Aboriginal and non-Aboriginal people.

Conclusion: Aboriginal people were more likely than non-Aboriginal people to be diagnosed with more advanced cancer for only a few cancer types, most notably head and neck cancers. Differences in spread of disease at diagnosis are unlikely to explain much of the survival differences observed across a wide range of cancers between Aboriginal and non-Aboriginal people in NSW.

the Aboriginal Health and Medical Research Council of NSW and NSW Health. ${ }^{10}$

\section{Methods}

This study was approved by the NSW Population and Health Services Research Ethics Committee and the Aboriginal Health and Medical Research Council Ethics Committee.

\section{Study cohort}

The study sample consisted of all adults diagnosed with a primary invasive cancer in NSW from 1 January 2001 to 31 December 2007. Details of 235449 cancers were extracted from the NSW Central Cancer Registry (CCR). Cases notified by death certificate or autopsy only (3575 cases) were excluded; similar proportions of cancers in Aboriginal (1.3\%) and non-Aboriginal $(1.5 \%)$ people were notified this way. As the CCR classifies stage of cancer by the extent of its spread beyond the organ of origin, only solid tumours were included, and 14263 lymphohaematopoietic cancers were excluded. Cancers of unknown primary site are all metastatic and were excluded (15907 people). The proportions of Aboriginal and non-Aboriginal people with unknown primary site were similar $(6.7 \%$ and $6.9 \%$, respectively). We also excluded 229 male breast cancers.

The remaining 201475 cancers were grouped, using the International Classification of Diseases for Oncology, third edition codes: prostate (C61); colorectal (C18-C20); breast (C50); melanoma (C44, with histology codes 8720-8780); lung (C33, C34); upper gastrointestinal tract $(\mathrm{C} 15-\mathrm{C} 17$, C22-C25); cervix (C53); urinary tract (C64-C68); head and neck (C00-C14, C30-C32); other gynaecological (C51, C52, C54-C59); eye, brain and central nervous system (C69-C72); and other solid tumours (C21, C26, C37-C41, C44 [excluding melanoma], C47-C49, C60, C62, C63, C73-C77). 
When people were diagnosed with multiple cancers in the same group, same month and at the same stage (eg, regional colon cancer and regional rectal cancer) only the first record was retained, so that an additional 232 cancers were excluded. When multiple cancers in the same group were diagnosed in the same month, but at different stages, the record for the cancer with known stage or the most advanced stage was retained, and 165 cancers were excluded. For people who were diagnosed with multiple cancers in the same group at different times, only the record for the first cancer was retained, and 486 cancers were excluded. All records were retained for people who were diagnosed with multiple cancers in different groups.

People with unknown Aboriginal status (6596 cases) or place of residence (three cases) were also excluded. The final sample comprised 193993 cancers in 187193 individuals.

\section{Record linkage}

To determine Aboriginal status, the cancer records were linked to records for inpatient admissions in the NSW Admitted Patient Data Collection (APDC) covering public and private hospitals for 1 July 2000 to 30 June 2009 and Australian Bureau of Statistics death records for NSW up to 31 December 2007. Probabilistic linkage of the CCR, APDC and death records was carried out by the Centre for Health Record Linkage (CHeReL) using ChoiceMaker software (ChoiceMaker Technologies).

\section{Study factors}

In our analysis, a person was determined to be Aboriginal if they were listed as Aboriginal and/or Torres Strait Islander in any of their APDC or death records. Details obtained from the CCR included month and year of diagnosis, age at diagnosis, sex, local government area (LGA) of residence, cancer type, spread of disease at diagnosis and histological findings. Spread of disease was recorded by the CCR as localised (the tumour was contained within the organ in which it originated), regional (the tumour had spread to surrounding organs, adjacent tissue and/or nearby lymph nodes), distant (metastatic disease) and unknown. ${ }^{4}$

LGA of residence at diagnosis was classified as major city, inner regional and rural (including outer regional, remote and very remote) using the Accessibility/Remoteness Index of Australia (ARIA+).${ }^{11}$ Socioeconomic disadvantage quintiles were assigned using the Australian Bureau of Statistics Socio-Economic Indexes for Areas (SEIFA) Index of Relative Socio-economic Advantage and Disadvantage corresponding to the LGA of residence. $^{12,13}$

\section{Statistical analysis}

To adjust for differences in the distribution of cancer types, we compared the numbers of Aboriginal people observed in each spread-of-disease category with the numbers that would be expected if Aboriginal people had the same likelihood of localised, regional, distant and unknown spread as non-Aboriginal people for each cancer type. To obtain the expected counts, multinomial logistic regression models were fitted using the data for non-Aboriginal people, and the predicted probabilities of localised, regional, distant or unknown spread of disease for each Aboriginal person were obtained from these models. To obtain the total expected counts for each spread-of-disease category, these probabilities were summed for all Aboriginal people. The first model included cancer type as the only explanatory variable. The second model also included sex, age group, year of diagnosis, socioeconomic disadvantage quintile and place of residence. Differences in the expected and observed counts were tested using the Pearson $\chi^{2}$ test.

For each cancer type, we also separately compared the relative risks of Aboriginal and non-Aboriginal people being diagnosed with regional, distant or unknown spread, compared with localised spread, using multinomial logistic regression, adjusting for sex, age group, year of diagnosis, socioeconomic disadvantage quintile and place of residence. For a sensitivity analysis, we repeated this analysis, including only people with known spread, as cancers with unknown spread may be a heterogeneous group.

All analyses were performed in $\mathrm{R}$ 3.0.0 $0^{14}$ and SAS version 9.3 (SAS Institute).

\section{Results}

Compared with non-Aboriginal people, Aboriginal people were more likely to be younger $(P<0.001)$, over three times more likely to live in rural areas and twice as likely to live in the most disadvantaged areas (Box 1). For Aboriginal people, lung cancer was the most common cancer and prostate cancer the fourth most common. For non-Aboriginal people, prostate cancer was the most common and lung cancer was the fifth most common.

For all cancers, $40.3 \%$ of Aboriginal people were diagnosed with localised spread compared with $46.6 \%$ of nonAboriginal people, an absolute difference of $6.3 \%$ (Appendix). The deficit in localised cancer in Aboriginal people was matched by excesses in cancers with regional spread (2.6\%) and distant spread (5.2\%), with a small deficit in unknown spread (-1.5\%). The differences in spread were reduced after accounting for the different distributions of cancer types. The observed proportions for Aboriginal people were $40.3 \%$ for localised, $23.3 \%$ for regional, $18.7 \%$ for distant and $17.7 \%$ for unknown spread (Appendix); however, after adjustment to the distribution of cancer types for nonAboriginal people, the expected proportions for Aboriginal people were $42.4 \%$ for localised, $21.8 \%$ for regional, $16.1 \%$ for distant and $19.6 \%$ unknown spread. These adjusted proportions changed little after age group, sex, year of diagnosis, place of residence and socioeconomic status were also taken into account $(42.5 \%$ localised, $22.4 \%$ regional, $16.0 \%$ distant and $19.1 \%$ unknown spread). The differences in spread of cancer between Aboriginal and non-Aboriginal people, however, were statistically significant $(P=0.002)$.

While for all cancers combined Aboriginal people were more likely than non-Aboriginal people to be diagnosed with more advanced cancers, for most cancer types, Aboriginal 
and non-Aboriginal people had similar spread of disease at diagnosis (Appendix). Aboriginal people with head and neck cancer were much more likely than non-Aboriginal people to be diagnosed with regional or distant spread (adjusted relative risk ratio [RRR]: 1.89 [95\% CI, 1.212.98] for regional spread; 3.40 [95\% CI, 1.85-6.05] for distant spread) (Box 2).

For breast, cervical and prostate cancers and melanoma, Aboriginal people had higher relative risks than non-Aboriginal people of being diagnosed with regional or distant spread, compared with localised spread, although the overall effect of Aboriginal status was not statistically significant (Box 2). Aboriginal people diagnosed with cancer of the urinary tract were less likely to have unknown spread compared with non-Aboriginal people. For lung, colorectal, upper gastrointestinal tract, other gynaecological, and eye, brain and central nervous system cancers, there were no trends of increasing relative risk ratios with more advanced spread and none were statistically significant for Aboriginal and non-Aboriginal people.

In the sensitivity analyses, where people with unknown spread were excluded, the results were similar for each cancer type, with the exception of breast cancer. For breast cancer, the differences in spread for Aboriginal and non-Aboriginal people were statistically significant $(P=0.03)$. Aboriginal people were more likely to have regional spread (adjusted RRR, 1.22; 95\% CI, 0.95-1.58) or distant spread (adjusted RRR, 1.79; 95\% CI, 1.13-2.73).

\section{Discussion}

We found that the differences in spread at diagnosis between Aboriginal and non-Aboriginal people were limited to a few cancer types. For most of the cancer types examined, including lung and colorectal cancers, there were no significant differences in spread of disease at diagnosis, suggesting that the difficulties in diagnosing these cancers early may apply equally to Aboriginal and non-Aboriginal people. While

1 Characteristics of Aboriginal and non-Aboriginal people diagnosed with solid tumours* in New South Wales, 2001-2007

\begin{tabular}{|c|c|c|c|}
\hline & Aboriginal, no. (\%) & Non-Aboriginal, no. (\%) & $P^{\dagger}$ \\
\hline Sex & & & 0.004 \\
\hline Female & $968(47.5 \%)$ & $84968(44.3 \%)$ & \\
\hline Male & 1071 (52.5\%) & 106986 (55.7\%) & \\
\hline Age at diagnosis (years) & & & $<0.001$ \\
\hline $18-49$ & $441(21.6 \%)$ & $24939(13.0 \%)$ & \\
\hline $50-59$ & $444(21.8 \%)$ & $33421(17.4 \%)$ & \\
\hline $60-69$ & $534(26.2 \%)$ & $48699(25.4 \%)$ & \\
\hline $70-79$ & $472(23.1 \%)$ & $52199(27.2 \%)$ & \\
\hline $80+$ & $148(7.3 \%)$ & $32696(17.0 \%)$ & \\
\hline Place of residence at diagnosis & & & $<0.001$ \\
\hline Major city & 871 (42.7\%) & 133889 (69.8\%) & \\
\hline Inner regional & $663(32.5 \%)$ & $44757(23.3 \%)$ & \\
\hline Rural & $505(24.8 \%)$ & 13308 (6.9\%) & \\
\hline Socioeconomic disadvantage & & & $<0.001$ \\
\hline Least disadvantaged & $139(6.8 \%)$ & $36295(18.9 \%)$ & \\
\hline Second least disadvantaged & $238(11.7 \%)$ & $41326(21.5 \%)$ & \\
\hline Third least disadvantaged & $273(13.4 \%)$ & 31455 (16.4\%) & \\
\hline Second most disadvantaged & $467(22.9 \%)$ & $39828(20.7 \%)$ & \\
\hline Most disadvantaged & $922(45.2 \%)$ & $43050(22.4 \%)$ & \\
\hline Cancer site & & & $<0.001$ \\
\hline Lung & $344(16.9 \%)$ & $19945(10.4 \%)$ & \\
\hline Breast (female) & $288(14.1 \%)$ & $27545(14.3 \%)$ & \\
\hline Colorectal & $278(13.6 \%)$ & $29531(15.4 \%)$ & \\
\hline Prostate & $259(12.7 \%)$ & $34986(18.2 \%)$ & \\
\hline Upper gastrointestinal tract & $237(11.6 \%)$ & $16625(8.7 \%)$ & \\
\hline Urinary tract & $119(5.8 \%)$ & $11162(5.8 \%)$ & \\
\hline Head and neck & $118(5.8 \%)$ & 7705 (4.0\%) & \\
\hline Melanoma & $99(4.9 \%)$ & $21041(11.0 \%)$ & \\
\hline Cervix & $53(2.6 \%)$ & $1580(0.8 \%)$ & \\
\hline Other gynaecological & $73(3.6 \%)$ & $7388(3.8 \%)$ & \\
\hline Eye, brain and central nervous system & $51(2.5 \%)$ & 3815 (2.0\%) & \\
\hline Other & $120(5.9 \%)$ & $10631(5.5 \%)$ & \\
\hline Method of diagnosis & & & 0.007 \\
\hline Histopathology & $1824(89.5 \%)$ & $175277(91.3 \%)$ & \\
\hline Cytology & $68(3.3 \%)$ & $4759(2.5 \%)$ & \\
\hline Clinical/imaging/biochemical & $147(7.2 \%)$ & $11918(6.2 \%)$ & \\
\hline
\end{tabular}

it is well reported that Aboriginal people are diagnosed with more advanced cancer than non-Aboriginal people, ${ }^{3,4}$ the reason for this finding is not yet clear.

Our finding that Aboriginal people were more likely to be diagnosed with advanced disease for only a subset of cancer types is consistent with previous findings. A study in Queensland found that compared with non-Aboriginal people matched on age, place of residence, year of diagnosis and cancer type, Aboriginal people were significantly more likely to have regional, distant or unknown spread of disease for all cancers combined. ${ }^{3}$ The Qld study, however, found similar spread of disease for 
2 Comparison of the relative risks of Aboriginal and non-Aboriginal people diagnosed with solid tumours having regional, distant or unknown spread of disease at diagnosis, compared with localised spread, in New South Wales, 2001-2007

\begin{tabular}{|c|c|c|c|}
\hline Cancer & Spread & Adjusted RRR $(95 \% \mathrm{Cl})$ & $P *$ \\
\hline \multirow[t]{3}{*}{ All cancers $^{\dagger}$} & Regional & $1.12(1.00-1.26)$ & 0.001 \\
\hline & Distant & $1.28(1.12-1.46)$ & \\
\hline & Unknown & $0.98(0.86-1.12)$ & \\
\hline \multirow[t]{3}{*}{ Lung } & Regional & $1.06(0.76-1.48)$ & 0.671 \\
\hline & Distant & $0.89(0.67-1.19)$ & \\
\hline & Unknown & $1.00(0.73-1.38)$ & \\
\hline \multirow[t]{3}{*}{ Breast (female) } & Regional & $1.22(0.94-1.57)$ & 0.076 \\
\hline & Distant & $1.78(1.12-2.72)$ & \\
\hline & Unknown & $1.14(0.69-1.80)$ & \\
\hline \multirow[t]{3}{*}{ Colorectal } & Regional & $0.86(0.65-1.14)$ & 0.642 \\
\hline & Distant & $1.01(0.72-1.40)$ & \\
\hline & Unknown & $0.84(0.52-1.29)$ & \\
\hline \multirow[t]{3}{*}{ Prostate } & Regional & $1.39(0.83-2.21)$ & 0.271 \\
\hline & Distant & $1.62(0.90-2.73)$ & \\
\hline & Unknown & $1.07(0.81-1.40)$ & \\
\hline \multirow[t]{3}{*}{ Upper gastrointestinal tract } & Regional & $0.77(0.52-1.12)$ & 0.491 \\
\hline & Distant & $0.99(0.70-1.39)$ & \\
\hline & Unknown & $0.90(0.61-1.31)$ & \\
\hline \multirow[t]{3}{*}{ Urinary tract } & Regional & $1.22(0.74-1.93)$ & 0.016 \\
\hline & Distant & $1.17(0.67-1.94)$ & \\
\hline & Unknown & $0.41(0.19-0.79)$ & \\
\hline \multirow[t]{3}{*}{ Head and neck } & Regional & $1.89(1.21-2.98)$ & $<0.001$ \\
\hline & Distant & $3.40(1.85-6.05)$ & \\
\hline & Unknown & $0.90(0.50-1.57)$ & \\
\hline \multirow[t]{3}{*}{ Melanoma } & Regional & $1.02(0.43-2.08)$ & 0.261 \\
\hline & Distant & $1.97(0.91-3.75)$ & \\
\hline & Unknown & $1.54(0.68-3.01)$ & \\
\hline \multirow[t]{3}{*}{ Cervical } & Regional & $1.42(0.71-2.77)$ & 0.074 \\
\hline & Distant & $2.70(1.07-6.25)$ & \\
\hline & Unknown & $0.63(0.21-1.59)$ & \\
\hline \multirow[t]{3}{*}{ Other gynaecological } & Regional & $1.14(0.59-2.08)$ & 0.487 \\
\hline & Distant & $1.20(0.68-2.08)$ & \\
\hline & Unknown & $0.59(0.20-1.40)$ & \\
\hline \multirow[t]{3}{*}{ Eye, brain and CNS } & Regional & $1.36(0.32-3.87)$ & 0.485 \\
\hline & Distant & $0.00(0.00-1.91)^{\ddagger}$ & \\
\hline & Unknown & $0.90(0.46-1.65)$ & \\
\hline \multirow[t]{3}{*}{ Other } & Regional & $1.04(0.59-1.73)$ & 0.121 \\
\hline & Distant & $1.82(1.04-3.04)$ & \\
\hline & Unknown & $0.85(0.51-1.39)$ & \\
\hline
\end{tabular}

RRR = relative risk ratio comparing Aboriginal with non-Aboriginal people, adjusted for sex, age group, year of diagnosis, socioeconomic disadvantage and place of residence. CNS = central nervous system.*From Type III likelihood ratio tests. $†$ Model also included cancer type. $¥ R R R=0$ as no Aboriginal people were diagnosed with distant spread eye, brain or CNS cancer. head and neck cancers, and higher proportions of unknown spread for Aboriginal people with lung cancer, while for all gynaecological cancers combined (including cervical cancer), Aboriginal women were more likely to be diagnosed at a more advanced stage. ${ }^{2,5,6}$ Another study found that Aboriginal people in the Northern Territory with non-Hodgkin lymphoma, colorectal, breast or cervical cancers were more likely to be diagnosed at a more advanced stage, but those with lung cancer were more likely to be diagnosed at an earlier stage. ${ }^{7}$ It is difficult to compare NSW with the NT and Qld as there are cultural and health care differences across regions, and Aboriginal people in NSW are more likely to reside close to health services.

Our finding that Aboriginal people with head and neck cancer were significantly more likely to be diagnosed with advanced disease than non-Aboriginal people differs from the finding in Qld. ${ }^{5}$ Spread of disease at diagnosis of head and neck cancers has been found to be associated with a range of factors, including ethnicity, age, socioeconomic status and frequency of dental visits. ${ }^{15,16} \mathrm{As}$ signs of oral and pharyngeal cancers can be detected during routine dental examinations, less frequent dental care for Aboriginal people ${ }^{17}$ could be an important factor in their later diagnosis. In the 2004-05 National Aboriginal and Torres Strait Islander Health Survey, $49 \%$ of Aboriginal people reported consulting a dentist in the previous 2 years compared with $66 \%$ of non-Aboriginal people. ${ }^{17}$

Differing levels of participation in organised cancer screening programs are likely to be factors in some of the differences we observed. Communities with high levels of participation generally have higher proportions of cancers diagnosed at localised stage, ${ }^{18,19}$ and participation in screening programs for breast, cervical and colorectal cancers is lower for Aboriginal than non-Aboriginal people. ${ }^{20-22}$ Our finding that Aboriginal women were more likely to be diagnosed with distant disease for breast and cervical cancer is consistent with lower screening rates for Aboriginal women. That our results 
do not suggest any effect of screening for colorectal cancer in the period 2001-2007 is unsurprising, as a limited screening program only commenced in NSW in 2006. ${ }^{22}$

There are potential limitations to this study that should be considered when interpreting the results. The results are limited by the high proportion of people with unknown spread of disease, and by the possibility of the misclassification of Aboriginal and non-Aboriginal people.

The unknown spread group, which was especially large for prostate cancer, is likely to include a mixture of different spreads of disease, ${ }^{23}$ and it is impossible to be sure of the effect of this group on the results.

While it is possible that a proportion of people may have been incorrectly classified as Aboriginal or non-Aboriginal, audits of the APDC suggest that this is a rare occurrence, ${ }^{24}$ and in our study the risk of misclassification of Aboriginal people is likely to be further reduced as they were classified based on all of their APDC or death records. While using deaths to identify Aboriginal people may have biased our findings away from the null hypothesis, as those with advanced disease are at higher risk of dying, our findings are in the opposite direction, with only small differences in spread of disease after accounting for differences in types of cancer. In addition, we do not expect any bias of this kind to be selective for head and neck cancers. We are therefore confident that this had no important influence in this study.

Major strengths of this study are that it was population based and a large number of cancer types were examined. It is also the first study to focus on differences in cancer spread at diagnosis between Aboriginal and non-Aboriginal people in NSW while also taking into account many of the factors known to be associated with spread of disease.

We found that Aboriginal people were more likely than non-Aboriginal people to be diagnosed with more advanced disease for all cancers combined. This was largely due to differences in the mix of cancer types and, to a lesser degree, more advanced disease for only a few cancer types. Differences in spread of disease at diagnosis are unlikely to fully explain the survival differences observed across a wide range of cancers in NSW. Individuals, communities and health professionals need to be vigilant in detecting cancer in Aboriginal people as early as possible and ensuring that they receive the best available treatment.

Acknowledgements: We acknowledge the chief investigators of the Aboriginal Patterns of Cancer Care (APOCC) project and the APOCC Aboriginal Advisory Group for providing advice on the content of this article. We thank Clare Kahn for reviewing and editing drafts of this article. Thank you to the following institutions for providing the data for this work: Cancer Institute NSW, the NSW Ministry of Health, Clinical Cancer Registries and hospitals in NSW. Thank you also to the Aboriginal Health and Medical Research Council of NSW for its ongoing support of this project. The APOCC project was funded by a National Health and Medical Research Council health services research grant (440202).

Competing interests: No relevant disclosures.

Received 13 May 2014, accepted 9 Sep 2014. 
1 Cunningham J, Rumbold AR, Zhang $X$, Condon JR. Incidence, aetiology, and outcomes of cancer in Indigenous peoples in Australia. Lancet Oncol 2008; 9: 585-595.

2 Moore SP, Diaz A, Green AC, et al. Indigenous women with gynaecological cancers have poorer survival than nonIndigenous women: explained by stage, comorbidity and treatment uptake [abstract]. Asia Pac J Clin Oncol 2012; 8 Suppl 3: 321.

3 Valery PC, Coory M, Stirling J, Green AC. Cancer diagnosis, treatment, and survival in Indigenous and nonIndigenous Australians: a matched cohort study. Lancet 2006; 367: 1842-1848.

4 Cancer Institute NSW. Cancer in NSW Aboriginal peoples: incidence, mortality and survival. Sydney: Cancer Institute NSW, 2012. http://www.cancerinstitute. org.au/media/207303/cancerinnswab originalpeaopleincidence,mortalityan dsurvival_27august2012.pdf (accessed Sep 2014).

5 Moore SP, Green AC, Garvey G, et al. A study of head and neck cancer treatment and survival among Indigenous and non-Indigenous people in Queensland, Australia, 1998 to 2004. BMC Cancer 2011; 11: 460.

6 Coory MD, Green AC, Stirling J, Valery PC. Survival of Indigenous and nonIndigenous Queenslanders after a diagnosis of lung cancer: a matched cohort study. Med J Aust 2008; 188: 562-566.

7 Condon JR, Barnes T, Armstrong BK, et al. Stage at diagnosis and cancer survival for Indigenous Australians in the Northern Territory. Med J Aust 2005; 182: $277-280$

8 Lyratzopoulos G, Abel GA, Barbiere JM, et al. Variation in advanced stage at diagnosis of lung and female breast cancer in an English region 2006-2009. Br J Cancer 2012; 106: 1068-1075.

9 Priest P, Sadler L, Sykes P, et al. Determinants of inequalities in cervical cancer stage at diagnosis and survival in New Zealand. Cancer Causes Control 2010; 21: 209-214.
10 NSW Department of Health. Communicating positively: a guide to appropriate Aboriginal terminology. Sydney: NSW Department of Health, 2004. http://www.health.nsw.gov. au/aboriginal/Publications/pubterminology.pdf (accessed Sep 2014).

1 Department of Health and Aged Care. Measuring remoteness: Accessibility/ Remoteness Index of Australia (ARIA). Revised edition. Canberra: Commonwealth of Australia, 2001. http://www.health.gov.au/internet/ main/publishing.nsf/Content/E2EE19F E831F26BFCA257BF0001F3DFA/\$File/ ocpanew14.pdf (accessed Sep 2014).

12 Australian Bureau of Statistics. Census of Population and Housing: SocioEconomic Indexes for Areas (SEIFA), Australia, 2001. Table AUS_lga_s01. xls. Canberra: ABS, 2006. (ABS Cat. No. 2033.0.55.001.) http://www.abs.gov. au/AUSSTATS/abs@.nsf/DetailsPage /2033.0.55.0012001?OpenDocument (accessed May 2012).

13 Australian Bureau of Statistics. Census of Population and Housing: SocioEconomic Indexes for Areas (SEIFA), Australia - data only, 2006. Table Local Government Area Index of Relative Socio-economic Advantage and Disadvantage, 2006. Canberra: ABS, 2008. (ABS Cat. No. 2033.0.55.001.) http://www.abs.gov.au/AUSSTATS/ abs@.nsf/DetailsPage/2033.0.55.001 2006?OpenDocument (accessed May 2012).

14 R Core Team. R: a language and environment for statistical computing. Vienna: R Foundation for Statistical Computing, 2013.

15 Chen AY, Schrag NM, Halpern M, et al. Health insurance and stage at diagnosis of laryngeal cancer: does insurance type predict stage at diagnosis? Arch Otolaryngol Head Neck Surg 2007; 133: 784-790.

16 Langevin SM, Michaud DS, Eliot M, et al. Regular dental visits are associated with earlier stage at diagnosis for oral and pharyngeal cancer. Cancer Causes Control 2012; 23: 1821-1829.
17 Australian Bureau of Statistics. National Aboriginal and Torres Strait Islander Health Survey 2004-05. Canberra: ABS, 2006. (ABS Cat. No. 4715.0.) http://www.ausstats.abs.gov. au/ausstats/subscriber.nsf/0/BlBCF4 E6DD320A0BCA25714C001822BC/\$Fi le/47150_2004-05.pdf (accessed Sep 2014).

18 Cole SR, Tucker GR, Osborne JM, et al. Shift to earlier stage at diagnosis as a consequence of the National Bowel Cancer Screening Program. Med J Aust 2013; 198: 327-330.

19 Esserman L, Shieh Y, Thompson I. Rethinking screening for breast cancer and prostate cancer. JAMA 2009; 302: 1685-1692.

20 Roder D, Webster F, Zorbas H, Sinclair S. Breast screening and breast cancer survival in Aboriginal and Torres Strait Islander women of Australia. Asian Pac J Cancer Prev 2012; 13: 147-155.

21 Coory MD, Fagan PS, Muller JM, Dunn NA. Participation in cervical cancer screening by women in rural and remote Aboriginal and Torres Strait Islander communities in Queensland. Med J Aust 2002; 177: 544-547.

22 Australian Government Department of Health and Ageing and Australian Institute of Health and Welfare. National Bowel Cancer Screening Program monitoring report 2008. Canberra: AlHW, 2008. (AlHW Cat. No. CAN 40.) http://www.aihw.gov.au/ publication-detail/?id= 6442468198 (accessed Sep 2014).

23 Luo Q, Yu XQ, Cooke-Yarborough C, et al. Characteristics of cases with unknown stage prostate cancer in a population-based cancer registry. Cancer Epidemiol 2013; 37: 813-819.

24 Australian Institute of Health and Welfare. Indigenous identification in hospital separations data: quality report. Canberra: AlHW, 2010. (AlHW Cat. No. HSE 85; Health Services Series No. 35.) http://www.aihw.gov.au/ publication-detail/?id=6442468330 (accessed Sep 2014). 